\title{
The effects of video lecture viewing strategies on cognitive load
}

\author{
Jamie Costley ${ }^{1} \cdot$ Mik Fanguy $^{2,3} \cdot$ Chris Lange $^{4} \cdot$ Matthew Baldwin $^{2}$ \\ Published online: 6 April 2020 \\ (c) The Author(s) 2020
}

\begin{abstract}
Ideally, instruction should be delivered in a way that reduces the processing of information that does not contribute to learning (extraneous load) and increases cognitive processing that contributes to learning (germane load). One way students might effectively manage extraneous load is through specific video lecture viewing strategies to control the flow of information. Extant research provides conflicting perspectives regarding the role of viewing strategies within video lectures in improving learning. This study analyzed survey responses from a group of university students $(n=2012)$ participating in online classes in South Korea and looked at the mediating effect of video lecture viewing strategies on the relationship between extraneous load and germane load. The results showed that viewing strategies mediated the relationship between extraneous load and germane load. When viewing strategies were added to the model, the large negative relationship between extraneous load and germane load reversed to become a small positive relationship, implying that the negative correlation between extraneous load and germane load can be largely mitigated by students engaging in specific viewing strategies to better understand the content.
\end{abstract}

Keywords Cognitive load · e-Learning · Extraneous load · Germane load · Korea · Viewing strategies

Mik Fanguy

mik@kaist.edu

1 Educational Research Lab, Prince Sultan University, Riyadh, Saudi Arabia

2 English as a Foreign Language (EFL) Department, Korea Advanced Institute of Science and Technology (KAIST), 291 Daehak-ro, Guseong-dong, Yuseong-gu, Daejeon, South Korea

3 The Department of Educational Research, Lancaster University, Lancaster, UK

4 Department of British and American Humanities, Dankook University, Yongin, South Korea 


\section{Introduction}

With the increasing prevalence of online learning environments worldwide, and the subsequent increase in the use of video lectures, online content must be delivered clearly and effectively in order to meet the needs of the students. Clear and effective instruction is particularly important in distance learning environments because attrition and waning interest and motivation among students are commonly reported due to feelings of isolation in online learning environments (Lee and Rha 2009; Russo and Benson 2005). Furthermore, unclear web-based design elements or superfluous instruction in e-learning may contribute to confusion among online learners (Cheon and Grant 2012; Gerjets and Scheiter 2003; Kester et al. 2005; Kizilcec et al. 2015; Mayer 2014; Moos 2009). Therefore, course content must be delivered clearly and effectively so that students can remain focused on information relevant to the learning process. Cognitive load theory can provide insight into e-learning instruction and its effects on how students process information due to its explanation of the cognitive processes that occur when learners transfer information from the working memory to the long-term memory (Cierniak et al. 2009).

Because there is a limited capacity for storing information in the working memory, high levels of cognitive load can inhibit learner attempts to transfer unclear or excessive information from the working memory to the long-term memory (Cierniak et al. 2009). The three elements that make up cognitive load theory are intrinsic load, extraneous load, and germane load (De Jong 2010; Sweller 2010; Sweller et al. 1998). Intrinsic load constitutes content complexity based on learners' prior knowledge of the subject matter, and high levels of intrinsic load may inhibit learners from processing the information they receive (De Jong 2010; Sweller and Chandler 1994; Sweller et al. 1998; van Merriënboer and Ayres 2005). Extraneous load occurs when poorly delivered instruction causes students to process information that is not essential to the learning process (Cierniak et al. 2009; Leppink et al. 2013; Schmeck et al. 2015). Germane load directly contributes to improved schema formation through cognitive effort, ultimately aiding the transfer of information from the working memory to the long-term memory (Kolfschoten et al. 2010; Leppink et al. 2013; Sweller et al. 1998).

When presented with unclear instruction that causes extraneous load, students may engage in a variety of viewing strategies in an attempt to gain a better understanding of the lecture content. In the case of online video lectures, students may employ viewing strategies by directly interacting with the e-learning interface. In the context of the present study, viewing strategies refer to behaviors by learners to help better process the learning materials they are engaging with in online lecture videos. Viewing strategies include behaviors such as selecting the content order, pausing, scrolling back and rewatching portions of the video lecture, scrolling forward and skipping ahead in the video lecture, speeding up the video playing rate, looking away from the screen to listen more carefully, splitting attention between text and images, temporary cessation of listening to focus on something on the screen, and filtering and scanning text to find specific information needed to make better sense of the content (Caspi et al. 2005; Costley et al. 2018; Hiltz and Turoff 1985; Kim 
et al. 2014a, b; Le et al. 2010; Lee 2007; Li et al. 2015; Seufert et al. 2007). The fact that students can use such strategies is generally thought to be an advantage of the use of video lectures over traditional face-to-face lectures, as video lectures are more easily manipulated in these ways (Schwan and Riempp 2004). However, these strategies may interfere with comprehension as well, possibly increasing extraneous load by causing a disruption, which may lead to a lowering of the students' comprehension of the contents (Caspi et al. 2005). Therefore, it is important to understand how viewing strategies affect students' cognitive processing, considering the possible benefits of viewing strategies in improving students' comprehension, along with the conflicting perspectives of their effects.

\section{Theoretical background}

\section{Instruction, cognitive load, and learning}

Clear instruction in e-learning contexts involves both the coherent delivery and appropriate use of technology. Technology should be used to bolster content delivery without creating extraneous load for students (Chen 2007; Mayer 2014). Although the use of media in online lectures has generally been shown to facilitate comprehension and recall (Brecht 2012; Day et al. 2006; Rasch and Schnotz 2009; Schnotz and Rasch 2005; van Gog et al. 2005), it has also been shown that when unnecessary content and complicated media are presented as part of instruction, learning is impeded due to the processing of extraneous content (Hughes et al. 2019; Mautone and Mayer 2001). From web-based learning specifically, instruction that leads to extraneous processing includes the delivery of excessive and irrelevant information (Mayer 2014; Ozan and Ozarslan 2016), overuse of hyperlinks embedded in text (Cheon and Grant 2012; Moos 2009), physical separation of electronic sources (Kizilcec et al. 2015; Mayer and Moreno 2003), inaccurate display of interface options (Cheon and Grant 2012), and lengthy, unsegmented video lectures (Mayer 2014; Mayer and Chandler 2001).

As a means of promoting clear instruction, many studies have utilized extraneous load as a proxy of instructional quality, both within offline and online learning contexts (Chandler and Sweller 1991; Cheon and Grant 2012; Kalyuga et al. 2003; Kalyuga et al. 1999; Mayer et al. 2001; Mayer and Moreno 1998, 2003; Moreno et al. 2001). The link between instruction and extraneous load is evident by the fact that instructional intervention can alter levels of extraneous load (Sweller 2005). Leppink et al. (2013) identified three main instructional issues that contribute to increased levels of extraneous load: unclear explanations or instructions, ineffective explanations or instructions with regard to learning, and explanations or instructions consisting of unclear language. Research that specifically focuses on web-based instructional procedures to reduce extraneous load in an effort to increase germane load have focused on the following areas, as outlined by Cheon and Grant (2012): providing useful directions and feedback (Swan 2001), using effective organizational strategies within the layout of the online learning platform (Chalmers 2003), 
and providing visual elements that complement the instruction rather than create extraneous processing (Norman 1998).

\section{Learning, instructional difficulty, and lecture viewing strategies}

In e-learning contexts, studies have shown that merely watching videos from start to finish may not be the best way for students to learn content (Owston et al. 2011; von Konsky et al. 2009). The use of viewing strategies serves as an alternative course of action learners can take to insure content comprehension. One such strategy used by online learners is learner-controlled pacing (options such as pausing, repeating, accelerating, and decelerating while viewing a video), which is beneficial to learning and may signal that the student is employing a successful learning strategy (Bailey et al. 2017; Cassidy and Bailey 2018; Kalyuga 2008; Schwan and Riempp 2004). Students may rewatch videos at a different speed as a learning strategy to reiterate points, to complete note-taking, and to remain focused (Bruff et al. 2013). Pauses can also be part of a strategy to encode information into meaningful units, enhancing student engagement and potentially performance (Budin 2016). In addition to pausing, a survey by Cardall et al. (2008) found that most respondents had increased the speed of video playback and reported that doing so was beneficial to their learning.

While pausing, fast forwarding, rewinding, and rewatching would intuitively seem to be advantages of online video delivery of lectures compared with traditional delivery, Caspi et al. (2005) found that students often regarded these features as disadvantageous. This was because utilizing these features often led to a loss of learning context, which requires additional cognitive processing. Kalyuga (2008) posits that utilizing viewing strategies may burden novice learners with extraneous cognitive load, thereby canceling out the expected benefits of learner-controlled pacing features. To add empirical evidence to these claims, Moreno and Valdez (2005) and Tabbers et al. (2004) found no benefit to utilizing learner-controlled pacing compared to system-controlled pacing (where students simply watch instructional videos with no means of regulating pace). In addition to pacing, other viewing strategies such as splitting attention between text and images can negatively affect students' ability to process information due to an increase in students' extraneous cognitive processing, as they attempt to integrate information from the separated sources into their working memories (Kizilcec et al. 2015; Mayer and Moreno 2003). Le et al. (2010) found that students who engaged in viewing strategies most frequently when viewing online videos showed the poorest performance in the courses, implying that viewing strategies may not be successful learning strategies.

\section{Overcoming poor instruction through lecture viewing strategies}

Confusing or poorly presented instruction in online learning environments may lead to more engagement in viewing strategies in order to alter the flow of information. Viewing strategies can be seen as a sign of student confusion caused by difficult or unclearly presented content (Kim et al. 2014a, b; Le et al. 2010; Li et al. 2015). Li et al. (2015) analyzed the lecture viewing strategies of students taking online 
classes and found several salient relationships between viewing strategies and the difficulty of online videos. First, the amount of change in playback speed selected by the viewer had a negative correlation with the perceived difficulty of the video. Second, they found numerous examples of videos where students paused frequently because they encountered problems while watching the video. Third, infrequent or large skips forward indicated a higher level of perceived difficulty with the video. Fourth, they found that longer rewatching duration indicated higher perceived difficulty, while more frequent rewatching indicated lower perceived video difficulty. Li et al. (2015) have also hypothesized that frequent rewatching may in fact be a "frame-seeking" strategy, where students are merely rewinding briefly for specific video frames.

Although there is debate about the exact length of student attention spans (Wilson and Korn 2007), it is certain that lapses in attention occur and that students often do not even complete the videos if instruction is not well designed (Bunce et al. 2010; Ruiter et al. 2017). This lapse in attention is known as "vigilance decrement" (Risko et al. 2012) and because of it, lecture videos that are longer than 20 min may be less effective. Ozan and Ozarslan (2016) found that students were more likely to complete shorter videos. Similarly, Kim et al. (2014b) found that long lecture videos led to a higher rate of student dropout, meaning that the student closed and stopped watching the video. More directly related to the present study, Ozan and Ozarslan (2016) found that when students are presented with longer online lecture videos, they were more likely to view the video by seeking forward or backward to find relevant content and to pass over content they deem irrelevant to their learning. Kim et al. (2014b) further suggest such seeking strategy by students may represent attempts to consume unnecessarily long videos in shorter, more digestible units. Among the numerous strategies students implement when viewing online videos, one of the most widespread and effective is rewatching (Smidt and Hegelheimer 2004). Repetition and summarization has been generally shown to increase student recall. For example, Patel et al. (2019) found that students who rewatched online video lectures earned higher scores on subsequent exams. In analyzing peaks in students' lecture viewing strategies, Kim et al. (2014b) found peaks in students' rewatching of video contents occurred during particularly confusing or interesting parts of lecture videos. This selective rewatching strategy represents an attempt by the students to repeat content, particularly when summaries are not provided by the instructor.

\section{The current study}

The present study looks at how video lecture viewing strategies mediate the relationship between extraneous load and germane load at the Open Cyber University (OCU) in South Korea. This university is the largest in South Korea and has 120,000 students participating in 400 classes (About OCU, n.d.). Students who attend OCU classes come from 1 of 23 traditional brick-and-mortar universities that make up the OCU consortium, and their online classes provide credit towards their degrees from the offline universities (Jung 2000). The 23 universities that make up the OCU 
provide the professors, design of the courses, and course materials (Jung and Rha 2001). There is much debate about the general application of video lecture viewing strategies, how they might be applied in large online classes, and how they might affect cognitive processing in those situations. For this reason, the present study takes data from a broad sample of students using online learning materials to gain insight into how viewing strategies may affect cognitive load in this context.

Viewing extraneous load as representation of instruction quality and germane load as representation of the processes that lead to better retention and higher order thinking skills, this study examined a variety of relationships within a South Korean e-learning environment. Included are the relationship between extraneous and germane load, the relationship between viewing strategies and germane load, and the relationship between extraneous load and viewing strategies. The primary purpose of this study is to examine the mediating effect of extraneous load on the relationship between viewing strategies and germane load. While much extant research regards viewing strategies as a sign of unclear instruction, this study claims that viewing strategies are effective in overcoming poor instruction. Moreover, it is hypothesized that viewing strategies mediate the relationship between extraneous and germane load as a method to improve learning when students are faced with unclear instruction. Therefore, the current study examines the following hypotheses.

\section{Research hypotheses}

1. Extraneous load is negatively correlated with germane load.

2. Viewing strategies are positively correlated with germane load.

3. Extraneous load is positively correlated with viewing strategies.

4. Viewing strategies mediate the relationship between extraneous load and germane load.

\section{Methods}

\section{Research procedures and data collection}

This research began with a small group of students $(n=10)$ participating in brief interviews about their experiences studying online at the OCU. The questions were open-ended, but revolved around their experiences of instruction and interaction with other learners or instructors. Student responses noticeably emphasized the lack of learner-to-learner interaction and the relative importance of the video lectures that made up a large part of the instruction in their classes. For this reason, we decided to focus on aspects of direct instruction in the OCU, specifically video lectures and how students used them. Following the interviews, 92 OCU students filled out a broad survey. The survey dealt with issues such as automated feedback systems, instructional design, and video lectures. The survey showed that there were aspects of instruction and student behavior that were of value to investigate; therefore, a larger survey was designed to be given to a large population of OCU students. 
This subsequent survey was more focused in its approach, dealing directly with cognitive load and how it may be affected. It is this subsequent survey that was used for the current study.

Prior to the collection of data used in this study, the authors viewed a random sample of 10 OCU video lectures from various disciplines to get a sense of the video lecture lengths and how the students can engage with the content. Within the 15 week semester, the lessons are displayed on a weekly basis with the average video lecture lasting between 20 and $30 \mathrm{~min}$. While there is some variety in the number of lectures per week, most classes have 11 weeks of instruction, and students watch 2 or 3 videos per week. The videos consist of a talking head (the professor) providing verbal, textual, and graphical content pertaining to the course. The main course page allows students to view and download supplemental material used for the class, including material containing hyperlinks from which students can select additional information about specific topics. Prior to the lesson, a "prior to learning" link is provided which gives general background information on the topic. During the actual video lecture, the students have the option to view supplemental information in the form of pop-up text. Students can also click on a link to access a summary of the lesson at the conclusion of the video lecture and take quizzes to assess their progress. Regarding the pacing of the course, the students are given the ability to bookmark portions of the lecture, skip parts of the lecture, select any time frame of the lecture from which they want to watch, select the speed at which they wish to watch, and re-watch specific parts.

The survey was first written in English and then translated into the language used in the OCU, which is Korean. An expert in e-learning and the OCU checked the translation. The Korean translation was found to be an accurate representation of the English items, and so the survey was input into a Google Sheets form. A link to the survey was then sent to the administrative offices of the OCU, who checked that the survey was appropriate for their students to take. The OCU administration accepted the survey and posted it on their main board with a message inviting students to participate in the research. The link was active for 1 month, during which time students who wished to complete surveys did so. After a month had passed, it was taken down.

\section{Participants}

OCU students who participated in this study did so by submitting surveys using Google Sheets. A total of 2689 students submitted surveys. From the 2689 surveys submitted, 613 failed to fill out some part of the survey that was relevant to this research and were removed from the analysis, leaving 2076 valid responses. In this research, outlier removal was performed using Mahalanobis, Cook's, and Leverage values. Linear regression of viewing strategies, and extraneous load onto germane load was used to generate Mahalanobis, Cook's, and Leverage values to look for outliers. Participants whose results met the standard for two or more of these tests were removed from the analysis, leaving 2012. Among the 677 discarded participants, there were no shared traits, except filling out the survey incompletely or being 
outliers in relation to this research. All of the following results and tables subsequent to this are generated from these 2012 valid subjects. Of the 2012, 1055 (52\%) were female and 957 (48\%) were male. The average age of the subjects that were a part of this study was 23.6, with a standard deviation of 3.4. The oldest subject was 63, and the youngest was 19. Prior research looking at the OCU found similar distributions of gender and age (Suh and Kim 2013). There was a wide variety of classes taken in the OCU by the students participating in this study. As a part of this research, students have been shown to take a similar distribution of courses as in other research into the OCU: liberal arts (33\%), social science (17\%), technology (15\%), lifestyle and health $(12 \%)$, management and business $(8 \%)$, foreign language $(7 \%)$, natural science $(6 \%)$, and design $(2 \%)$.

\section{Models}

This research examines hypotheses that are shown using the path diagrams found in Fig. 1a, b. Figure 1a illustrates the total effect of extraneous load on germane load for students studying at the OCU. In keeping with Hypothesis 1, this figure

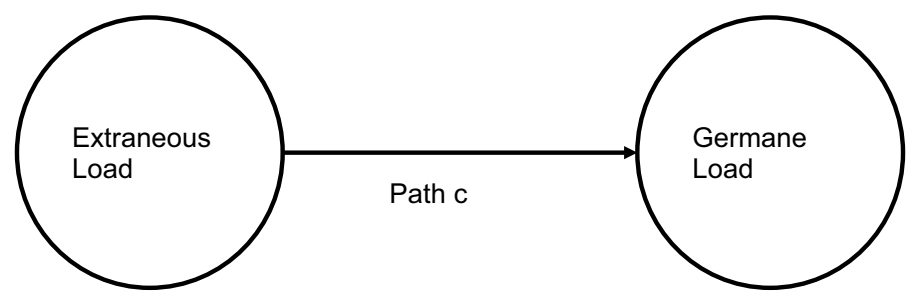

(a)

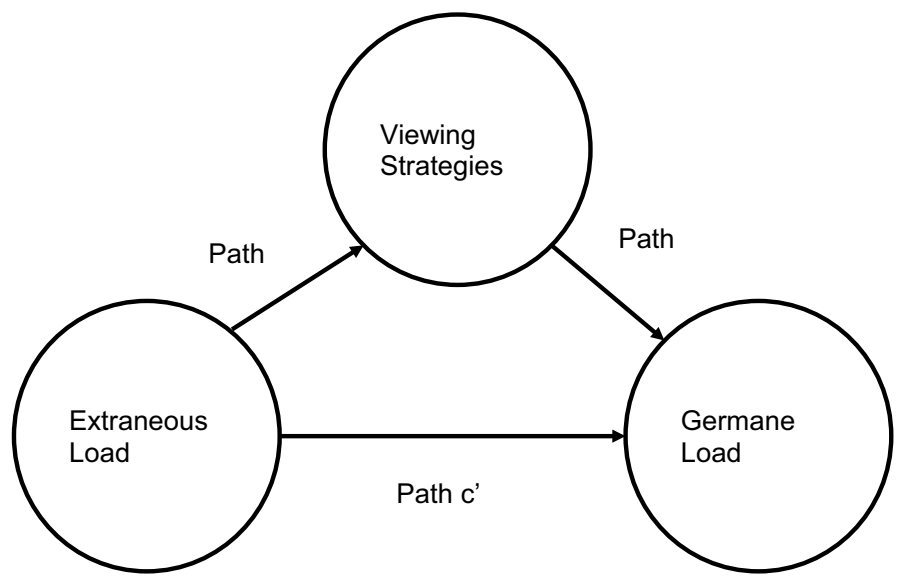

(b)

Fig. 1 a Total (c), b direct ( $\left.c^{\prime}\right)$ effect of extraneous load on germane load 
suggests that high levels of extraneous load are negatively associated with germane load. However, this research proposes that the relationship between extraneous load and germane load can be better understood through the inclusion of a third mediating variable, viewing strategies. The inclusion of this mediating variable allows us to obtain a more developed understanding of how extraneous load affects germane load by disaggregating the total effect (Path c) into two distinct effects: direct effects (Path c) and indirect effects (Paths a and b). These effects are illustrated in Fig. 1b. Figure 1b shows that extraneous load will have some indirect effect on germane load. First, higher levels of extraneous load will increase levels of viewing strategies (Path a), and, in turn, higher levels of viewing strategies will increase students' levels of germane load (Path b). These indirect relationships are addressed by Hypotheses 2 and 3. The balance of extraneous loads' total effect upon germane load is likely to occur via a direct relationship between these two variables, as shown by Path c' in Fig. 1b.

To gain a deeper understanding of the relationships used in this study, this research uses Baron and Kenny's (1986) three equation method to model mediation. Furthermore, the present study also follows a process known as the Porumbescu Equation (Porumbescu 2017).

Step 1 The dependent variable should be regressed on to the independent variable to assess whether or not the independent variable is a statistically significant predictor of the dependent variable.

Independent variable $\rightarrow$ dependent variable.

$$
Y=\beta_{10}+\beta_{11} X+\varepsilon_{2}
$$

$\beta_{11}$ is significant.

Step 2 The mediating variable should be regressed on to the independent variable to assess whether or not the independent variable is a statistically significant predictor of the mediating variable. If there is no relationship at this stage, then clearly the mediator does not mediate anything.

Independent variable $\rightarrow$ mediating variable

$$
M e=\beta_{20}+\beta_{21} X+\varepsilon_{2}
$$

$\beta_{21}$ is significant

Step 3 The dependent variable should be regressed on to the mediating variable and the independent variable to assess whether or not the mediating variable is a statistically significant predictor of the dependent variable, and the relationship between the independent variable and dependent variable from Step 1 is significantly reduced or absent.

$$
Y=\beta_{30}+\beta_{31} X+\beta_{32} M e+\varepsilon_{3}
$$

$\beta_{32}$ is significant. $\beta_{31}$ Should be smaller than the original relationship between the independent and dependent variables $\left(\beta_{11}\right)$.

Another perspective, or way of describing the above is that there are four criteria that must be met for mediation to have occurred: (1) the relationship between the independent and dependent variable must be statistically significant, without 
the inclusion of the mediator, (2) the independent variable and mediator must have a statistically significant relationship, (3) the mediator and the dependent variable must have a statistically significant relationship, and (4) the relationship between the independent and the dependent variable is significantly reduced or disappears when controlling for the mediator.

\section{Instrument development}

Five students who were part of the initial interview section of this research were asked to discuss possible viewing strategies they might engage into help them understand the lecture. From this discussion, a list of five items was drawn up that the students all agreed seemed to cover the likely strategies they might engage into increase comprehension while watching the lectures. To generate the indicators for measuring viewing strategies, five Likert-style items were used: (1) I had to scan my eyes back and forth between the text and the graphs/images in the videos I watched; (2) I sometimes had to pause the video to read something on the PPT/whiteboard; (3) I had to rewatch some parts of the lecture to fully understand it; (4) I sometimes had to look away from the screen to listen more carefully; and (5) I sometimes had to stop listening to focus on something on the screen. The research participants were asked to score how strongly they agreed with the statements on a scale of 1-7. The five indicators were summed and then divided by the number of items (5), and it is this final combined construct that was used to measure levels of viewing strategies in this research. Cronbach's alpha was also calculated for the combined construct at .865 , which is appropriate for this type of research.

To create both the germane load and extraneous load constructs, items from Leppink et al.'s (2013) paper, The development of an instrument for measuring cognitive load were used. Leppink et al.'s (2013) paper lays out the uses and applications of the three main types of cognitive load (intrinsic, extraneous, and germane) and items for measuring them. These items are designed to measure student perceived levels of cognitive load. Seven of those items were used in the current research, three for extraneous load and four for germane load. The germane load construct's items were as follows: (1) The lecture really enhanced my understanding of the topic; (2) The lecture really enhanced my knowledge and understanding of the of the class subject; (3) The lecture really enhanced my understanding of the concepts associated with the class subject; and (4) The lecture really enhanced my understanding of concepts and definitions. The extraneous load construct's items were as follows: (1) The explanations during the lecture were very unclear; (2) The explanations were, in terms of learning, very ineffective; and (3) The explanations were full of unclear language. The current study uses a slight variation in wording from Leppink et al.'s (2013), in that, where we use the word "lecture", the original wording from Leppink et al.'s (2013) survey used the word "activity". This was done to make the items more appropriate for the learning context of the OCU. The Cronbach's alpha for the germane load construct was .926, and the Cronbach's alpha for the extraneous load construct was .928 , both of which are acceptable for this type of research. 
Leppink et al. (2013) performed exploratory factor analysis to get a better sense of how the varying aspects of cognitive load relate to one another. The loadings for intrinsic load, extraneous load, and germane load all represented independent robust factors, which is reflective of the triarchic theory of cognitive load that provides for the separate measurement of different elements of cognitive load (Deleeuw and Mayer 2008). However, questions have been raised about the true representation of Leppink et al.'s (2013) items, as recent research has claimed that germane load may actually be a representation of intrinsic load rather than cognitive effort that contributes to understanding content. This claim is based on the idea that within germane load measurements, effort does not contribute to the internal consistency of the construct (Kalyuga 2011; Leppink et al. 2014). Debue and van de Leemput (2014), however, refute this claim by showing that Leppink et al.'s (2013) germane load items were related to an increase in performance created by higher levels of cognitive effort rather than knowledge of the content based on complexity. Justification for the current study is based on the findings by Debue and van de Leemput (2014).

Mental effort also plays a role in extraneous load (Larmuseau et al. 2019), which brings Leppink et al.'s (2013) conceptualization of extraneous load into question due to the fact that their extraneous load items are heavily reflective of poor instruction regardless of effort. Other research has addressed this issue by focusing on mental effort calculations rather than instructional explanations alone (Kalyuga and Sweller 2005; Paas 1992; Rikers et al. 2004; van Merriënboer and Sweller 2005). Aware of this concern, Leppink et al. (2014) conducted a follow-up study to their 2013 research to look into whether the three extraneous load items reflected not only unclear instruction, but also mental effort to understand such instruction. They found that effort to understand difficult instruction contributed to the internal consistency of the overall extraneous load factor. Providing justification for the present study, Leppink et al.'s (2014) claim is that the underlying assumption with respect to their original construct is that high levels of extraneous load are reflective of mental effort unsuccessfully put forth by the students to understand unclear instruction.

\section{Factor analysis}

Exploratory Factor Analysis was used in this study. The Maximum Likelihood Method with Promax rotation was used to extract the factors for the three components. Three well-recognized criteria were used for the factor analysis. The Bartlett's Test of Sphericity was significant (c2=5043.79, $p<.001)$, and the Kaiser-Meyer-Olkin Measure (KMO) of sampling adequacy was .85, above the recommended value of .6 (Kline 2015). No commonalities were observed below .50. After running factor analysis, one item (I had to scan my eyes back and forth between the text and the graphs/images in the videos I watched) loaded below the commonly used cutoff point of .400 and was consequently removed (Hair et al. 2006). Analysis was run once more and resulted in items loading in their respective categories. Table 1 displays the pattern matrix. 
Table 1 Matrix for items

Viewing strategies

Re-watch some parts of the lecture to fully understand it

.780

.693

Pause the video to read something on the PPT/whiteboard

.514

Look away from the screen to listen more carefully

Extraneous cognitive load

The explanations during the lecture were very unclear

The explanations were full of unclear language

Germane cognitive load

Enhanced my understanding of the topic

Enhanced my knowledge and understanding of the of the class subject

\section{Results}

Descriptive statistics for this research are shown in Table 2. The mean for student's level of germane cognitive load was 3.60, meaning that students were largely neutral in how much they had felt they had learnt from their classes. The mean for extraneous cognitive load was higher at 4.48, showing that students felt there was some degree of unnecessary cognitive processing from their lectures in the OCU. The mean level of video lecture viewing strategies was 4.36 , which demonstrates that learners engaged in a variety of viewing strategies while watching the online video lectures.

The results of the three regression equations used in the mediation analysis for the current study can be seen in Table 3. All variables shown are standardized. For all three equations, the $F$ values are statistically significant $(p<.01)$, and the adjusted $\mathrm{r}^{2}$ values range from .05 to .46 . These values suggest that all the equations that are used as a part of this research are statistically significant and explain variation in the data to some degree.

The first model, Eq. 1, shows that higher levels of extraneous cognitive load are negatively associated with levels of germane cognitive load (Path c: total

Table 2 Descriptives and correlation tables $(\mathrm{n}=2012)$

\begin{tabular}{|c|c|c|c|c|c|c|c|}
\hline & & Range & Mean & $\mathrm{SD}$ & 1 & 2 & 3 \\
\hline 1 & Extraneous load & $1-7$ & 4.4829 & 1.16753 & 1 & & \\
\hline 2 & Germane load & $1-7$ & 3.5978 & 1.32651 & $-.31 * *$ & 1 & \\
\hline 3 & Viewing strategies & $1-7$ & 4.4132 & 1.24779 & $.16^{* *}$ & $.59 * *$ & 1 \\
\hline
\end{tabular}

$* * p<.01$ 
Table 3 Mediation table

\begin{tabular}{llll}
\hline & $\begin{array}{l}\text { Equation 1 } \\
\text { Germane load }\end{array}$ & $\begin{array}{l}\text { Equation 2 } \\
\text { Viewing strategies } \\
\text { (Path c) }\end{array}$ & $\begin{array}{l}\text { Equation 3 } \\
\text { Germane load }\end{array}$ \\
\hline Extraneous load & $-.31^{*}$ & $.16^{*}$ & (Paths c and b) \\
Viewing strategies & & & 0.08 \\
Constant & 2.39 & 4.08 & $.59^{*}$ \\
$F$ value & 232.6 & 17.49 & 4.14 \\
Adjusted $\mathrm{r}^{2}$ & 0.22 & 0.05 & 779.22 \\
$\mathrm{~N}$ & 2012 & 2012 & 0.47 \\
\hline
\end{tabular}

$* p<.01$

effect). The mediating variable (viewing strategies) is not present in this regression. This result provides support for the idea that increasing levels of extraneous load will have a negative effect on students' learning in the form of germane cognitive load. Referring back to Baron and Kenny's (1986) criteria for mediation, the first criterion, that the relationship between the independent and dependent variable be statistically significant $(p<.01)$, is satisfied.

The second model, Eq. 2, shows that students' viewing strategies are positively correlated with levels of extraneous cognitive load. This suggests that increasing the levels of extraneous cognitive load will increase the amount of viewing strategies the students engage in when watching the video lectures. The fact that this equation (Path a) is significant satisfies the second criterion for mediation. Models 1 and 2 both offer strong evidence for the significance of extraneous cognitive load in student outcomes and behavior.

The third model has two main findings of interest. First, Eq. 3 shows that students' level of germane cognitive load is positively correlated with their viewing strategies $(p<.01)$, which is shown in Path b of Fig. 1b. To this end, it was found that the more students engaged in viewing strategies, the higher their germane cognitive load. This satisfies the third criterion for mediation. The second finding of interest from Eq. 3 is that, when controlling for viewing strategies, the large negative relationship between extraneous cognitive load and future germane cognitive load reverses to become a small positive relationship (-.31 to .08). This satisfies the fourth criterion for mediation and establishes that this model meets all the criteria for mediation. When a model is completely mediated, the inclusion of the mediation variable (Path c) completely removes the relationship between the independent and dependent variable. In the current study, the relationship was not completely removed; however, it changed direction.

These three equations and four paths give strong evidence of a mediation effect (Path c'). This implies that the negative correlation between extraneous cognitive load and germane cognitive load can be largely mitigated by students engaging in viewing strategies. 


\section{Discussion}

The survey responses collected in the present study shed light on relationships among clarity of instruction, video lecture viewing strategies, and learning. If we consider extraneous load as a measurement of the clarity of instruction, viewing strategies as a mediating strategy used by students in dealing with complex or unclear information, and germane load as a measurement of learning, the conclusions of this study are as follows: extraneous load was negatively correlated with germane load, viewing strategies were positively correlated with extraneous load, viewing strategies were positively correlated with germane load, and viewing strategies positively mediated the relationship between extraneous load and germane load. The negative correlation between extraneous and germane load is in line with research showing that unclear instruction leads to decreased learning in e-learning environments, particularly when instruction causes unnecessary processing due to irrelevant or redundant presentation of the material (Mautone and Mayer 2001; Mayer et al. 2001; Mayer and Moreno 2003). Empirical research also supports the positive relationship found between extraneous load and student viewing strategies. Most studies tend to treat viewing strategies as an indication that students find instruction complicated or unclear (Kim et al. 2014a, b; Le et al. 2010; Li et al. 2015). For example, when faced with lengthy lecture videos, students tend to engage in frame-seeking to order to locate relevant content (Kim et al. 2014b; Ozan and Ozarslan 2016). Frame-seeking is a viewing strategies that requires cognitive effort that is not directly connected to learning.

The results of the present study show that viewing strategies positively correlate with germane load, suggesting that such behaviors are not only coping mechanisms for poor instruction, but also successful strategies that increase levels of germane cognitive load. This result seems to contradict the work of Le et al. (2010) and $\mathrm{Li}$ et al. (2015), who found that certain viewing strategies utilized with high frequency were indicators of decreased understanding of course content. Instruction that is presented in an unclear or ineffective manner puts extraneous cognitive demands on students (Leppink et al. 2013). The viewing strategies that students employ to overcome such instruction can create an additional cognitive burden for learners that may negate the potential advantages that they are expected to provide (Kalyuga 2008).

The final aspect of the present study is that the survey results indicate that viewing strategies positively mediate the relationship between extraneous and germane load. As suggested in the literature, viewing strategies may not always signal confusion on the part of the learner, but may instead represent points of interest or topics viewed as important to the learner (Kim et al. 2014b). Students may also utilize viewing strategies as part of larger learning strategies to take more complete notes or to better understand the lecture content (Bruff et al. 2013; Budin 2016; Veletsianos et al. 2016). While such suggestions seem plausible, to our knowledge, the present study is the first to demonstrate empirical evidence of positive meditation between extraneous and germane load via viewing strategies. As extraneous load occupies valuable cognitive processing power that could 
instead be devoted to germane load, the present paper demonstrates that viewing strategies are an effective response for students in situations of increased extraneous load, such as unclear instruction. The present results do not indicate whether viewing strategies are equally useful for both high- and low-achieving learners. While it is possible, as suggested by Kalyuga (2008), that novice learners may be additionally burdened cognitively by the option to control the pacing of video instruction, it may also be the case that without the option of using viewing strategies, such learners would have learned even less effectively.

\section{Conclusion}

The results of this study show that video lecture viewing strategies are a useful learning strategy to improve students' cognitive processing, even in instances of increased extraneous cognitive load. For all the advice imparted on video lecture producers to make content as clear as possible, as this medium of instruction increases in popularity, poor examples will persist. The contribution of the present study is that it provides empirical evidence that students who engage in viewing strategies can increase their learning, even when instruction is presented in an unclear or ineffective manner. In the same way that skimming and scanning are strategies used by readers to derive main ideas or specific information, respectively, viewing strategies can be seen as a potential solution to this problem of poor instruction.

While these findings are valuable to instructors, content developers, and students, the present research has several limitations. This study relied on self-reported information regarding viewing strategies, unlike other studies on MOOCs that enabled the researchers to track users clicks within the video viewing window (Guo et al. 2014; Kim et al. 2014a; Le et al. 2010; Li et al. 2015). While self-reported data gives a sense of whether students engaged in viewing strategies or what types of strategies they engaged in, it does not provide as detailed a picture of precisely when, in what way, and how frequently such strategies were performed. In addition, the mediating of viewing strategies between extraneous and germane load was rather weak and may not signify a substantial change in student learning. For this reason, research that uses controlled experiments varying the levels of extraneous load can help to further develop our understanding of the relationships found in the present study. Future studies can also look into issues related to the inclusion of intrinsic cognitive load into the research model to understand how all aspects of cognitive load interact with students' lecture view strategies.

The cultural and technological contexts in South Korea may have also affected the results, as it is the nation with the world's highest bandwidth per capita (Tan 2016). Therefore, South Koreans may have relatively high awareness of online environments, enabling South Koreans to feel more comfortable with online learning contexts when compared to students from less IT-developed regions. Such familiarity could affect how students interact with online lecture videos, so it would be useful to examine the effects of student viewing strategies on learning in online environments in other cultural and technological contexts as well. Lastly, the results of this study do not distinguish between the effects of using viewing strategies by 
high- and low-achieving students. It is possible that viewing strategies are an excellent learning technique for high-level learners but an additional cognitive burden for low-level learners, as suggested by Kalyuga (2008). Future research should be conducted to examine the effects of viewing strategies on learners with varying levels of proficiency.

However, the present findings suggest that viewing strategies are a valuable tool for students to increase their learning in online and flipped classrooms. The authors, therefore, propose further research be conducted to formulate a systematic way to teach the application of viewing strategies. This could potentially enable students to not only acquire the salient points from ineffectively presented online lectures, but to navigate the huge volume of information students encounter in their day-to-day lives in this modern age.

\section{Compliance with ethical standards}

Conflict of interest The authors declare that they have no conflict of interest.

Ethical approval The methods used in this study were approved by the Open Cyber University and adhere to the ethics policies of the institution.

Informed consent All respondents of collected surveys were informed of their rights and participated voluntarily.

Open Access This article is licensed under a Creative Commons Attribution 4.0 International License, which permits use, sharing, adaptation, distribution and reproduction in any medium or format, as long as you give appropriate credit to the original author(s) and the source, provide a link to the Creative Commons licence, and indicate if changes were made. The images or other third party material in this article are included in the article's Creative Commons licence, unless indicated otherwise in a credit line to the material. If material is not included in the article's Creative Commons licence and your intended use is not permitted by statutory regulation or exceeds the permitted use, you will need to obtain permission directly from the copyright holder. To view a copy of this licence, visit http://creativecommons.org/licen ses/by/4.0/.

\section{References}

About OCU. (n.d.). In Open Cyber University. Retrieved February 17, 2016 from http://www.ocu.ac.kr/ foreign/english/About_ocu/sub05.asp.

Bailey, D., Park, I., \& Haji, S. A. (2017). An investigation of Facebook for language learning: Better understanding perceptions and participation. CALL-EJ, 18(2), 14-30.

Baron, R. M., \& Kenny, D. A. (1986). The moderator-mediator variable distinction in social psychological research: Conceptual, strategic, and statistical considerations. Journal of Personality and Social Psychology, 5(6), 1173-1182.

Brecht, H. D. (2012). Learning from online video lectures. Journal of Information Technology Education, 11(1), 227-250.

Bruff, D. O., Fisher, D. H., McEwen, K. E., \& Smith, B. E. (2013). Wrapping a MOOC: Student perceptions of an experiment in blended learning. Journal of Online Learning and Teaching, 9(2), 187.

Budin, S. (2016). Stop and pause for engagement in online video lectures. In K. Thompson, \& B. Chen (Eds.), Teaching online pedagogical repository. Orlando, FL: University of Central Florida Center 
for Distributed Learning. Retrieved June 25, 2019, from https://topr.online.ucf.edu/index.php?title =Stop_and_pause_for_engagement_in_online_video_lectures\&oldid=5132.

Bunce, D. M., Flens, E. A., \& Neiles, K. Y. (2010). How long can students pay attention in class? A study of student attention decline using clickers. Journal of Chemical Education, 87(12), 1438-1443.

Cardall, S., Krupat, E., \& Ulrich, M. (2008). Live lecture versus video-recorded lecture: Are students voting with their feet? Academic Medicine, 83(12), 1174-1178.

Caspi, A., Gorsky, P., \& Privman, M. (2005). Viewing comprehension: Students' learning preferences and strategies when studying from video. Instructional Science, 33(1), 31-47. https://doi. org/10.1007/s11251-004-2576-X.

Cassidy, R., \& Bailey, D. (2018). L2 Students' perceptions and practices of both giving and receiving online peer-feedback. Multimedia-Assisted Language Learning, 21(1), 11-34.

Chalmers, P. A. (2003). The role of cognitive theory in human-computer interface. Computers in Human Behavior, 19(5), 593-607.

Chandler, P., \& Sweller, J. (1991). Cognitive load theory and the format of instruction. Cognition and Instruction, 8(4), 293-332.

Chen, S. J. (2007). Instructional design strategies for intensive online courses: An objectivist-constructivist blended approach. Journal of Interactive Online Learning, 6(1), 72-86.

Cheon, J., \& Grant, M. M. (2012). The effects of metaphorical interface on germane cognitive load in web-based instruction. Educational Technology Research and Development, 60(3), 399-420.

Cierniak, G., Scheiter, K., \& Gerjets, P. (2009). Explaining the split-attention effect: Is the reduction of extraneous cognitive load accompanied by an increase in germane cognitive load? Computers in Human Behavior, 25, 315-324.

Costley, J., Fanguy, M., Baldwin, M., Lange, C., \& Han, S. (2018). The role of motivation in the use of lecture behaviors in the online classroom. Journal of Information Technology Education: Research, 17(1), 471-484.

Day, J. A., Foley, J. D., \& Catrambone, R. (2006). Investigating multimedia learning with web lectures. GVU technical report GIT-GVU-06-25. GA: Georgia Institute of Technology. Retrieved December 27, 2018, from http://smartech.gatech.edu/handle/1853/13141.

De Jong, T. (2010). Cognitive load theory, educational research, and instructional design: Some food for thought. Instructional Science, 38(2), 105-134.

Debue, N., \& van De Leemput, C. (2014). What does germane load mean? An empirical contribution to the cognitive load theory. Frontiers in Psychology, 5, 1-12.

DeLeeuw, K. E., \& Mayer, R. E. (2008). A comparison of three measures of cognitive load: Evidence for separable measures of intrinsic, extraneous, and germane load. Journal of Educational Psychology, $100(1), 223$.

Gerjets, P., \& Scheiter, K. (2003). Goal configurations and processing strategies as moderators between instructional design and cognitive load: Evidence from hypertext-based instruction. Educational Psychologist, 38(1), 33-41.

Guo, P. J., Kim, J., \& Rubin, R. (2014). How video production affects student engagement: An empirical study of MOOC videos. In Proceedings of the first ACM conference on learning@ scale (pp. 41-50). ACM.

Hair, J. F. J., Black, W. C., Babin, B. J., Anderson, R. E., \& Tatham, R. L. (2006). Multivariate data analysis (Vol. 6th). New Jersey, NJ: Pearson Education Inc.

Hiltz, S. R., \& Turoff, M. (1985). Structuring computer-mediated communication systems to avoid information overload. Communications of the ACM, 28(7), 680-689.

Hughes, C., Costley, J., \& Lange, C. (2019). The effects of multimedia video lectures on extraneous load. Distance Education, 40(1), 54-75.

Jung, I. (2000). Korea: Virtual university trial project. TechKnowLogia, 2, 29-31.

Jung, I., \& Rha, I. (2001). A virtual university trial project: Its impact on higher education in South Korea. Innovations in Education and Teaching International, 38(1), 31-41.

Kalyuga, S. (Ed.). (2008). Managing cognitive load in adaptive multimedia learning. Hershey, PA: IGI Global.

Kalyuga, S. (2011). Cognitive load theory: How many types of load does it really need? Educational Psychology Review, 23(1), 1-19.

Kalyuga, S., Ayres, P., Chandler, P., \& Sweller, J. (2003). The expertise reversal effect. Educational Psychologist, 38(1), 23-31.

Kalyuga, S., Chandler, P., \& Sweller, J. (1999). Managing split-attention and redundancy in multimedia instruction. Applied Cognitive Psychology, 13, 351-371. 
Kalyuga, S., \& Sweller, J. (2005). Rapid dynamic assessment of expertise to improve the efficiency of adaptive e-learning. Educational Technology Research and Development, 53(3), 83-93.

Kester, L., Kirschner, P. A., \& Merriënboer, J. J. (2005). The management of cognitive load during complex cognitive skill acquisition by means of computer-simulated problem solving. British Journal of Educational Psychology, 75(1), 71-85.

Kim, J., Guo, P. J., Cai, C. J., Li, S. W. D., Gajos, K. Z., \& Miller, R. C. (2014a). Data-driven interaction techniques for improving navigation of educational videos. In Proceedings of the 27th annual ACM symposium on user interface software and technology (pp. 563-572). ACM.

Kim, J., Guo, P. J., Seaton, D. T., Mitros, P., Gajos, K. Z., \& Miller, R. C. (2014b). Understanding invideo dropouts and interaction peaks in online lecture videos. In Proceedings of the first ACM conference on learning@scale (pp.31-40). ACM.

Kizilcec, R. F., Bailenson, J. N., \& Gomez, C. J. (2015). The instructor's face in video instruction: Evidence from two large-scale field studies. Journal of Educational Psychology, 107(3), 724-739. https ://doi.org/10.1037/edu0000013.

Kline, R. B. (2015). Principles and practice of structural equation modeling (4th ed.). New York, NY: Guilford publications.

Kolfschoten, G., Lukosch, S., Verbraeck, A., Valentin, E., \& Vreede, G. J. D. (2010). Cognitive learning efficiency through the use of design patterns in teaching. Computers and Education, 54(3), 652-660.

Larmuseau, C., Vanneste, P., Cornelis, J., Desmet, P., \& Depaepe, F. (2019). Combining physiological data and subjective measurements to investigate cognitive load during complex learning. Frontline Learning Research, 7(2), 57-74.

Le, A., Joordens, S., Chrysostomou, S., \& Grinnell, R. (2010). Online lecture accessibility and its influence on performance in skills-based courses. Computers and Education, 55(1), 313-319.

Lee, J. (2007). The effects of visual metaphor and cognitive style for mental modeling in a hypermediabased environment. Interacting with Computers, 19(6), 614-629.

Lee, H. J., \& Rha, I. (2009). Influence of structure and interaction on student achievement and satisfaction in web-based distance learning. Educational Technology and Society, 12(4), 372-382.

Leppink, J., Paas, F., van der Vleuten, C. P., van Gog, T., \& van Merriënboer, J. J. (2013). Development of an instrument for measuring different types of cognitive load. Behavior Research Methods, 45(4), 1058-1072.

Leppink, J., Paas, F., van Gog, T., van Der Vleuten, C. P., \& van Merriënboer, J. J. (2014). Effects of pairs of problems and examples on task performance and different types of cognitive load. Learning and Instruction, 30, 32-42.

Li, N., Kidzinski, L., Jermann, P., \& Dillenbourg, P. (2015). How do in-video interactions reflect perceived video difficulty? In Proceedings of the European MOOCs stakeholder summit 2015 (No. EPFL-CONF-207968, pp. 112-121). PAU Education.

Mautone, P. D., \& Mayer, R. E. (2001). Signaling as a cognitive guide in multimedia learning. Journal of Educational Psychology, 93(2), 377-389.

Mayer, R. E. (2014). Cognitive theory of multimedia learning. In R. E. Mayer (Ed.), The Cambridge handbook of multimedia learning (pp. 43-71). New York: Cambridge University Press.

Mayer, R. E., \& Chandler, P. (2001). When learning is just a click away: Does simple user interaction foster deeper understanding of multimedia messages? Journal of Educational Psychology, 93(2), 390.

Mayer, R. E., Heiser, J., \& Lonn, S. (2001). Cognitive constraints on multimedia learning: When presenting more material results in less understanding. Journal of Educational Psychology, 93(1), 187198. https://doi.org/10.1037/0022-0663.93.1.187.

Mayer, R. E., \& Moreno, R. (1998). A split-attention effect in multimedia learning: Evidence for dual processing systems in working memory. Journal of Educational Psychology, 90(2), 312-320. https ://doi.org/10.1037//0022-0663.90.2.312.

Mayer, R. E., \& Moreno, R. (2003). Nine ways to reduce cognitive load in multimedia learning. Educational Psychologist, 38(1), 43-52.

Moos, D. C. (2009). Note-taking while learning hypermedia: Cognitive and motivational considerations. Computers in Human Behavior, 25(5), 1120-1128.

Moreno, R., Mayer, R. E., Spires, H. A., \& Lester, J. C. (2001). The case for social agency in computer-based teaching: Do students learn more deeply when they interact with animated pedagogical agents? Cognition and Instruction, 19(2), 177-213.

Moreno, R., \& Valdez, A. (2005). Cognitive load and learning effects of having students organize pictures and words in multimedia environments: The role of student interactivity and feedback. Educational Technology Research and Development, 53(3), 35-45. 
Norman, D. (1998). The design of everyday things. New York, NY: Doubleday.

Owston, R., Lupshenyuk, D., \& Wideman, H. (2011). Lecture capture in large undergraduate classes: Student perceptions and academic performance. The Internet and Higher Education, 14(4), 262-268.

Ozan, O., \& Ozarslan, Y. (2016). Video lecture watching behaviors of learners in online courses. Educational Media International, 53(1), 27-41.

Paas, F. G. (1992). Training strategies for attaining transfer of problem-solving skill in statistics: A cognitive-load approach. Journal of Educational Psychology, 84(4), 429.

Patel, B., Yook, G., Mislan, S., \& Persky, A. M. (2019). Exploring the consequences on memory of students who know they have access to recorded lectures. American Journal of Pharmaceutical Education, 83(5), 6958.

Porumbescu, G. (2017). Not all bad news after all? EXPLORING the relationship between citizens' use of online mass media for Government Information and Trust in Government. International Public Management Journal, 20, 1-33.

Rasch, T., \& Schnotz, W. (2009). Interactive and non-interactive pictures in multimedia learning environments: Effects on learning outcomes and learning efficiency. Learning and Instruction, 19(5), $411-422$.

Rikers, R. M., van Gerven, P. W., \& Schmidt, H. G. (2004). Cognitive load theory as a tool for expertise development. Instructional Science, 32(1-2), 173-182.

Risko, E. F., Anderson, N., Sarwal, A., Engelhardt, M., \& Kingstone, A. (2012). Everyday attention: Variation in mind wandering and memory in a lecture. Applied Cognitive Psychology, 26(2), 234-242.

Ruiter, M., Loyens, S., \& Paas, F. (2017). The effects of cycling on a desk bike on attention, retention and mood during a video lecture. Applied Cognitive Psychology, 31(6), 593-603.

Russo, T., \& Benson, S. (2005). Learning with invisible others: Perceptions of online presence and their relationship to cognitive and affective learning. Educational Technology and Society, 8(1), 54-62.

Schmeck, A., Opfermann, M., van Gog, T., Paas, F., \& Leutner, D. (2015). Measuring cognitive load with subjective rating scales during problem solving: Differences between immediate and delayed ratings. Instructional Science, 43(1), 93-114.

Schnotz, W., \& Rasch, T. (2005). Enabling, facilitating, and inhibiting effects of animations in multimedia learning: Why reduction of cognitive load can have negative results on learning. Educational Technology Research and Development, 53(3), 47-58.

Schwan, S., \& Riempp, R. (2004). The cognitive benefits of interactive videos: Learning to tie nautical knots. Learning and Instruction, 14(3), 293-305.

Seufert, T., Jänen, I., \& Brünken, R. (2007). The impact of intrinsic cognitive load on the effectiveness of graphical help for coherence formation. Computers in Human Behavior, 23(3), 1055-1071.

Smidt, E., \& Hegelheimer, V. (2004). Effects of online academic lectures on ESL listening comprehension, incidental vocabulary acquisition, and strategy use. Computer Assisted Language Learning, 17(5), 517-556.

Suh, S., \& Kim, S. (2013). Study on policy for an entrance quota of cyber universities. Seoul, Korea: Korea Educational Information and Research Service.

Swan, K. (2001). Virtual interaction: Design factors affecting student satisfaction and perceived learning in asynchronous online courses. Distance Education, 22(2), 306-331.

Sweller, J. (2005). Implications of cognitive load theory for multimedia learning. In R. E. Mayer (Ed.), The Cambridge handbook of multimedia learning (pp. 19-30). New York: Cambridge University Press.

Sweller, J. (2010). Element interactivity and intrinsic, extraneous, and germane cognitive load. Educational Psychology Review, 22(2), 123-138.

Sweller, J., \& Chandler, P. (1994). Why some material is difficult to learn. Cognition and Instruction, 12(3), 185-233.

Sweller, J., van Merriënboer, J. J. G., \& Paas, F. (1998). Cognitive architecture and instructional design. Educational Psychology Review, 10, 251-296.

Tabbers, H. K., Martens, R. L., \& van Merriënboer, J. J. (2004). Multimedia instructions and cognitive load theory: Effects of modality and cueing. British Journal of Educational Psychology, 74(1), 71-81.

Tan, M. (2016). Turning point for a regime of rightlessness? In Y. Kim (Ed.), Routledge handbook of Korean culture and society (pp. 162-176). London and New York: Routledge.

van Gog, T., Ericsson, K. A., Rikers, R. M. J. P., \& Paas, F. (2005). Instructional design for advanced learners: Establishing connections between the theoretical frameworks of cognitive load and 
deliberate practice. Educational Technology Research and Development, 53(3), 73-81. https://doi. org/10.1007/BF02504799.

van Merriënboer, J. J., \& Ayres, P. (2005). Research on cognitive load theory and its design implications for e-learning. Educational Technology Research and Development, 53(3), 5-13.

van Merriënboer, J. J., \& Sweller, J. (2005). Cognitive load theory and complex learning: Recent developments and future directions. Educational Psychology Review, 17(2), 147-177.

Veletsianos, G., Reich, J., \& Pasquini, L. A. (2016). The life between big data log events: Learners' strategies to overcome challenges in MOOCs. AERA Open, 2(3), 2332858416657002.

von Konsky, B. R., Ivins, J., \& Gribble, S. J. (2009). Lecture attendance and web based lecture technologies: A comparison of student perceptions and usage patterns. Australasian Journal of Educational Technology, 25(4), 581-595.

Wilson, K., \& Korn, J. H. (2007). Attention during lectures: beyond ten minutes. Teaching of Psychology, 34(2), 85-89. https://doi.org/10.1080/00986280701291291.

Publisher's Note Springer Nature remains neutral with regard to jurisdictional claims in published maps and institutional affiliations.

Jamie Costley is a researcher in the Educational Research Lab at Prince Sultan University. He is interested in the effects of collaborative learning on cognitive load and student development in online environments.

Mik Fanguy is a visiting professor in the English as a Foreign Language Program at the Korea Advanced Institute of Science and Technology (KAIST) in South Korea. His research interests include collaborative writing and online learning.

Chris Lange is an assistant professor in the Department of British and American Humanities at Dankook University in South Korea. He has published papers on informal group work, e-learning instructional design, and the effects of learning strategies within online environments. His current research is focused on the effects of cognitive load and learner control within e-learning environments.

Matthew Baldwin is a visiting professor in the English as a Foreign Language Program at the Korea Advanced Institute of Science and Technology (KAIST). His research interests include EMI/integrated content and language, international education, online learning and flipped class instruction. 